\title{
O Legado Walloniano em Lacan: o Estágio do Espelho e a Prematuração
}

\author{
Crístia Gonçalves Lopes Corrêa ${ }^{1}$ \\ ${ }^{1}$ Universidade Federal de Juiz de Fora, MG, Brasil.
}

\author{
Richard Theisen Simanke ${ }^{1}$ \\ ${ }^{1}$ Universidade Federal de Juiz de Fora, MG, Brasil.
}

\begin{abstract}
Resumo: $\mathrm{O}$ artigo apresenta uma análise conceitual e estrutural de textos selecionados de Lacan e de Wallon, a fim de identificar evidências da influência exercida por Wallon sobre a teoria do imaginário elaborada por Lacan nos anos 1930 e 1940. No entanto, discutem-se também os pontos de discordância entre os dois. Para isso, o artigo aborda especificamente os temas da imagem especular e da prematuração na experiência vivida pela criança no estágio do espelho. Foi realizada análise comparativa dos trabalhos dos dois autores, destacando a influência da Psicologia do Desenvolvimento de Wallon sobre as formulações iniciais de Lacan acerca das funções da imagem especular e da prematuração. Trata-se, enfim, de identificar as implicações dessas conexões teóricas en tre a teoria do imaginário desenvolvida por Lacan em sua obra inicial e a psicologia do desenvolvimento de Wallon e de defender a relevância dessas contribuições para a compreensão desse momento específico da construção do corpus lacaniano. A importância e os desdobramentos dessa influência não parecem ter sido ainda detalhadamente examinados pela literatura da área.
\end{abstract}

Palavras-chave: Jacques Lacan, Henri Wallon, Imagem Especular, Prematuração.

\section{The Wallonian Legacy in Lacan: the Mirror Stage and Prematurity}

\begin{abstract}
This article presents a conceptual and structural analysis of selected texts by Lacan and Wallon in order to find evidence of the influence exerted by Wallon on the theory of the imaginary developed by Lacan in the 1930s and 1940s. However, the points of disagreement between them are addressed as well. For this, the article specifically addresses the issues of the mirror image and prematurity in the child's experience with the mirror stage. A comparative analysis of the works of the two authors was made, highlighting the influence of Wallon's developmental psychology on Lacan's early formulations on the functions of the mirror image and prematurity. Finally, it is a question of identifying the implications of these theoretical connections between the theory of the imaginary developed by Lacan in his early work and Wallon's developmental psychology and to argue for the relevance of these contributions to the understanding of this specific moment of the construction of the Lacanian corpus. The importance and the ramifications of this influence do not seem to have yet been examined in detail by the literature of the field.
\end{abstract}

Keywords: Jacques Lacan, Henri Wallon, Mirror Image, Prematurity.

\section{El Legado Walloniano em Lacan: el Estádio del Espejo y la Prematuración}

Resumen: El artículo presenta un análisis conceptual y estructural de textos seleccionados de Lacan y de Wallon, a fin de identificar evidencias de la influencia ejercida por Wallon sobre la teoría del imaginario elaborada por Lacan en los años 1930 y 1940. Sin embargo, se discuten también los puntos de desacuerdo entre los dos. Para ello, el artículo aborda específicamente 
los temas de la imagen especular y de la prematuración en la experiencia vivida por el niño en el estadio del espejo. Se realizó un análisis comparativo de los trabajos de los dos autores, destacando la influencia de la psicología del desarrollo de Wallon sobre las formulaciones iniciales de Lacan acerca de las funciones de la imagen especular y de la prematuración. Se trata, en fin, de identificar las implicaciones de esas conexiones teóricas entre la teoría del imaginario desarrollada por Lacan en su obra inicial y la psicología del desarrollo de Wallon y de defender la relevancia de esas contribuciones para la comprensión de ese momento específico de la construcción del corpus lacaniano. La importancia y los desdoblamientos de esa influencia no parecen haber sido todavía detalladamente examinados por la literatura del área.

Palabras clave: Jacques Lacan, Henri Wallon, Imagen Especular, Prematuración.

\section{Introdução}

$\mathrm{O}$ artigo de Jacques Lacan intitulado "O estágio do espelho como formador da função do eu” (Lacan, 1949/1966) é considerado comumente como o texto por excelência para sua abordagem do estágio do espelho. No entanto, trata-se aí de uma retomada dessa noção que traz modificações importantes com relação a suas formulações anteriores, do período entre 1936 e 1949, marcadas ainda por um tom fortemente psicológico. Entre estas, destaca-se o encaminhamento para uma abordagem estruturalista, afastando-se da perspectiva mais próxima a uma psicologia do desenvolvimento anteriormente adotada (Simanke, 2002).

Nesse período anterior a 1949, uma das principais referências de Lacan foi, com certeza, a obra de Henri Wallon (1879-1962). Contudo, apesar de serem amplamente reconhecidas a influência e até mesmo a presença do vocabulário emprestado de Wallon nas elaborações lacanianas iniciais sobre o estágio do espelho, o que se encontra na literatura são, frequentemente, apenas alusões breves e escassamente contextualizadas às eventuais contribuições ali encontradas por Lacan. Essas alusões, em geral, se restringem ao tema das funções da imagem especular no desenvolvimento da criança, sem a devida problematização das aproximações e distanciamentos entre as duas teorias (Jorge \& Ferreira, 2005).

Inegavelmente, nem tudo que Lacan propõe em sua teoria do imaginário se explica pela psicologia do desenvolvimento de seu tempo. Embora a influência desta última seja considerável, ela é, ainda assim, localizada e seletiva: "A partir dali, o percurso de Lacan seguiu seu próprio desenvolvimento, de uma originalidade irredutível a qualquer influência assinalável" (Jalley, 2011, p. 14). Além disso, Lacan, diversas vezes, retomará o tema do estádio do espelho em momentos em que sua referência a Wallon já se encontra ultrapassada. Como exemplo, pode-se mencionar a "audaciosa tentativa de aprofundamento teórico dos dados anteriores relativos ao estádio do espelho, baseados em um 'modelo óptico inspirado pela ilusão conhecida como 'buquê invertido' descrito por Bouasse” (Jalley, 2011). Mas a dívida de Lacan para com a psicologia de Wallon é real e também afirmada por Roudinesco (1985), que argumenta que a elaboração lacaniana das duas categorias do imaginário e do simbólico lhe deve muito. Embora citeWallon apenas uma vez nos textos do período pesquisado (Lacan, 1948/1966), Lacan dá diversos indícios de que conhecia em primeira mão pelo menos o artigo "Comment se développe chez l'enfant la notion du corps propre" (Wallon, 1931/1963) e o livro As origens do caráter na criança (Wallon, 1934/1971).

Dentre os temas essenciais que tornam pertinente o estudo comparativo entre as formulações teóricas de Lacan e Wallon, podem-se mencionar as funções da imagem especular a a prematuração do recém-nascido (Jalley, 2011), que desempenham, em ambos, um papel central em suas teorias. Elas se prestam, assim, para avaliar tanto suas similaridades quanto suas diferenças. Assim, com o objetivo de contribuir para o resgate desse aspecto do percurso inicial de Lacan, este artigo visa avaliar as contribuições da teoria de Wallon às formulações lacanianas a propósito dos temas da imagem especular e da prematuração.

\section{Método}

A pesquisa teve, inicialmente, um caráter exploratório, devido à carência de estudos históricos acerca do tema. Trata-se de um tipo de pesquisa científica que busca "levantar informações sobre um determinado objeto, delimitando assim um campo de trabalho" (Severino, 2007, p. 123). A investigação desenvolveu-se por meio de pesquisa bibliográfica, primeiramente 
abordando o conjunto dos textos lacanianos em que se formulou a teoria do imaginário defendida por ele nos anos 1930 e 1940 (Lacan, 1936/1966, 1938/1985, 1948/1966, 1949/1966, 1950/1966). A seguir, foram analisadas as obras de Wallon em que os temas da imagem especular e da prematuração aparecem de forma proeminente (Wallon, 1925/2007, 1931/1963, 1934/1971, 1941/1955, 1975).

Para alcançar o objetivo, o artigo apresenta uma análise conceitual e estrutural de textos selecionados de Lacan e de Wallon, a fim de identificar na obra do primeiro as evidências da influência exercida pelo segundo, assim como os pontos discordantes entre os dois autores. Por isso, essa análise inicial em separado dos trabalhos dos dois autores foi seguida de uma análise comparativa de suas concepções. Para essa última, os poucos autores que destacam a influência da psicologia de Wallon sobre o pensamento inicial de Lacan serão utilizados, tanto instrumentalmente, para a compreensão das questões conceituais envolvidas, quanto para comparação e contraste com as conclusões aqui alcançadas.

\section{Imagem especular e prematuração nas formulações lacanianas do estágio do espelho entre 1936 a 1949}

A primeira versão da formulação lacaniana do estádio do espelho data de agosto de 1936, quando da participação de Lacan no congresso da Associação Psicanalítica Internacional em Marienbad, em que apresentou um trabalho intitulado $O$ estádio do espelho. Mas o trabalho não foi enviado por Lacan para publicação nos anais do congresso. Entre as indicações disponíveis sobre o conteúdo dessa primeira versão da teoria do estágio do espelho, contam-se as extensas notas tomadas pela psicanalista francesa Françoise Dolto (1908-1988), quando da apresentação do trabalho na Sociedade Psicanalítica de Paris, anterior à do congresso de Marienbad. A primeira versão publicada pormenorizada da teoria se encontra no verbete "A família", que foi publicado na edição de 1938 da Encyclopédie française e republicado muito mais tarde sob a forma do livro Os complexos familiares na formação do indivíduo (Lacan, 1938/1985). Este texto foi escrito para o oitavo tomo da Encyclopédie française, no qual Wallon, responsável pelo volume dedicado à Psicologia (La vie mentale), convidou Édouard Pichon (1890-1940), Daniel Lagache (1903-1972) e Jacques Lacan para escreverem os capítulos concernentes à psicanálise. Mais especificamente, coube a Pichon o verbete "A psicanálise"; a Lagache, "A sexualidade"; e a Lacan foi confiado o verbete "A família". Nesse trabalho, a fase do espelho é apresentada como associada ao declínio do complexo de desmame ou, mais exatamente, situada no contexto do complexo da intrusão, tendo como pano de fundo a prematuração ao nascer do indivíduo humano:

$\mathrm{O}$ atraso do desenvolvimento do sistema nervoso central durante os seis primeiros meses provoca no bebê um estado de miséria psicológica, ligado à descoordenação motora. A falta prolongada de coordenação dos aparelhos fornece a base de uma proprioceptividade que dá o corpo como despedaçado. Daí o desenvolvimento de tendências direcionadas a qualquer rejuntamento do corpo próprio. O estádio do espelho ao mesmo tempo exprime e ultrapassa uma forma de "crise biológica" característica do desenvolvimento da espécie humana (Jalley, 2011, pp. 39-40).

Desse modo, para Lacan, o narcisismo, tal como reinterpretado por meio da noção de estágio do espelho, representa a antecipação imaginária de uma representação corporal coordenada e funcional, em contraste com a experiência proprioceptiva de um organismo que padece da prematuridade biológica. Essa experiência, por sua vez, se expressa na fantasia do corpo fragmentado ou despedaçado (corps morcelê). O narcisismo provê, assim, um tipo de sutura para a desagregação subjetiva provocada pelo trauma do desmame, que colocara o sujeito numa situação de desamparo. Correspondendo, na sucessão dos complexos, ao complexo da intrusão, a formulação do estágio do espelho fornece uma base conceitual para pensar a constituição imaginária do eu no contexto de uma relação de rivalidade - a situação prototípica é o nascimento do irmão. Essa relação de rivalidade enseja, correlativamente à constituição do eu pela identificação especular, a constituição imaginária do outro: "A relação constitutiva com o outro é, primariamente, uma relação de disputa" (Lacan, 1938/1985, p. 266). Nesse momento conceitual, o rival se cristaliza na figura do irmão (Sales, 2005). Esse é o sentido da assertiva: "o eu se constitui ao mesmo tempo em que o outro no drama do ciúme" (Lacan, 1938/1985, p. 269). Esse drama se exprime na disputa por um objeto, que passa a ser investido pelo desejo apenas por ser desejado pelo outro. 
Em 1946, numa intervenção nas jornadas psiquiátricas de Bonneval, Lacan retoma a discussão das características fundamentais do estágio do espelho. Essa intervenção foi publicada depois como o trabalho intitulado Formulações sobre a causalidade psíquica, que introduz a noção de transitivismo como um aspecto peculiar da assimilação pela criança da imagem especular: "a forma cativante de uma verdadeira captação pela imagem do outro" (Lacan, 1950/1966, p. 182). O transitivismo é um comportamento em queé possível observar a equivalência, para a criança, entre sua ação e a ação do outro. Ela diz, por exemplo, "François bateu em mim”, ao passo que foi ela quem bateu em François. Há nesse comportamento transitivista como que um espelho instável entre a criança e seu semelhante.

Em A agressividade em psicanálise, Lacan (1948/1966) destaca exatamente essa captação pela imago da forma humana que domina toda a dialética do comportamento da criança na presença de seu semelhante, fazendo notar as reações emocionais e os testemunhos articulados de um transitivismo normal no âmbito dessa experiência especular. Além disso, destaca que nessa captação pela imagem se delineia o primeiro momento da dialética das identificações, que está ligado a um fenômeno de Gestalt, à percepção muito precoce da forma humana pela criança. Esta "fixa seu interesse desde os primeiros meses e mesmo, no que tange ao rosto humano, desde o décimo dia de vida" (p. 115). Mas, para Lacan, são a jubilação triunfante e o interesse lúdico pela imagem especular no encontro da criança com sua imagem no espelho que evidenciam a operação de reconhecimento como crucial na gênese da subjetividade. Esse encontro, desde o sexto mês de vida, se caracteriza por esses sinais de jubilação triunfante e pelo caráter lúdico da experiência:

Essa conduta contrasta vivamente com a indiferença manifestada pelos animais que percebem essa imagem, como o chimpanzé, por exemplo, quando eles têm a experiência de sua inutilidade objetal, e ganha ainda mais destaque por se produzir numa idade em que a criança ainda apresenta, quanto ao nível de sua inteligência instrumental, um atraso em relação ao chimpanzé, com quem só se iguala aos 11 meses (Lacan, 1948/1966, p. 115).

A Tese IV desse artigo enuncia: "A agressividade é a tendência correlativa a um modo de identificação a que chamamos narcísico, e que determina a estrutura formal do eu do homem e do registro de entidades característico de seu mundo" (p. 112). Essa tese explicita a relação postulada por Lacan entre identificação narcísica e agressividade. A agressividade que se manifesta na rivalidade adviria da vivência da discrepância entre a síntese representada pela imagem especular e as sensações corporais da criança que dão origem a uma experiência de fragmentação. Lacan (1948/1966) afirma que a forma do estágio do espelho se cristaliza na tensão conflitiva experimentada pelo sujeito, que determina o despertar de seu desejo pelo objeto do desejo do outro:

O concurso primordial se precipita numa concorrência agressiva, e é dela que nasce a tríade do outro, do eu e do objeto, que, fendendo o espaço da comunhão especular, inscreve-se nela segundo um formalismo que lhe é próprio, e que domina a tal ponto a Einfühlung afetiva que a criança nessa idade pode desconhecer a identidade das pessoas que lhe são mais familiares, caso elas lhe apareçam num meio inteiramente modificado (p.116).

A relação com o outro será, pois, ambivalente: erótica e agressiva, sendo a agressividade direcionada ao outro igualmente direcionada a si mesmo. "Enfim, para Lacan, a relação narcísica já é a relação com o outro, já é amá-lo e odiá-lo simultaneamente, porque implica tanto identificação quanto agressividade" (Sales, 2005, p. 123). Por conseguinte, para Lacan, nesse momento, a gênese da agressividade se situa nessa constituição simultânea do eu narcísico e do outro, tanto como objeto quanto como parceiro na relação intersubjetiva. Esse artigo é o único do período de produção lacaniana em análise em que Wallon é textualmente citado. Mas, ainda assim, "não naquilo que tange a questões relativas à imagem especular" (Oliveira, 2017, p. 37). Na passagem em questão, a série de manifestações corporais desencadeadas em virtude da agressividade deve ser compreendida numa ordem de coordenação mais ampla: "a que subordinará as funções de posturas tônicas e de tensão vegetativa a uma relatividade social cuja prevalência Wallon sublinhou consideravelmente na constituição expressiva das emoções humanas" (Lacan, 1948/1966, p. 115).

Lacan faz uma nova comunicação no congresso da Associação Psicanalítica Internacional em Zurique, 
resultando em uma nova versão da teoria, apresentada no trabalho O estádio do espelho como formador da função do eu. Lacan (1949/1966) retoma o fato destacado em 1948 de a criança ser capaz de reconhecer como sua uma imagem no espelho e de se interessar por essa imagem justamente numa fase em que é superada pelo chimpanzé em termos de inteligência instrumental. O símio, por sua vez, desloca sua atenção do espelho rapidamente tão logo se dá conta da irrealidade da imagem. A criança reconhece sua imagem no espelho com uma manifestação de euforia e júbilo, ao mesmo tempo que efetua uma operação de identificação no sentido da "transformação produzida no sujeito quando ele assume uma imagem" (p. 97). O autor continua:

A assunção jubilatória de sua imagem especular por esse ser ainda mergulhado na impotência motora e na dependência da amamentação que é o filhote do homem nesse estágio de infans parecer-nos-á, pois, manifestar, numa situação exemplar, a matriz simbólica em que o $[e u]$ se precipita numa forma primordial, antes de se objetivar na dialética da identificação com o outro e antes que a linguagem lhe restitua, no universal, sua função de sujeito (Lacan, 1949/1996, p. 97).

O processo de identificação envolve uma função de antecipação exercida pela Gestalt corporal, produzindo uma miragem de maturação da potência do sujeito. Essa Gestalt é mais constituinte do que constituída. Sua eficácia é atestada por um experimento biológico: a transição da forma solitária para a forma gregária do gafanhoto migratório, dentro de uma mesma linhagem. Essa transição ocorre ao indivíduo ser exposto, numa certa fase de seu ciclo vital, à ação visual exercida pela imagem do semelhante, "desde que ela seja animada por movimentos de um estilo suficientemente próximo dos que são próprios à sua espécie" (p. 99). Nessa direção, Lacan argumenta que esse é um fato que caracteriza uma identificação homeomórfica. Verstegen (2015) argumenta que a presença de um mecanismo para suturar a realidade representa um contraste com a ênfase posterior sobre a subjetividade dividida.

Ao apresentar esses dados, Lacan (1949/1966) argumenta que o poder formador da imagem se exerce sobre o ser humano num grau ainda maior do que com animais como o gafanhoto. A razão para isso é sua prematuridade biológica. A imagem desempenharia justamente a função de suprir as deficiências ocasionadas pela neotenia - antecipação da maturidade sexual ao restante do desenvolvimento - e pela fetalização - preservação de características juvenis na forma adulta - do indivíduo humano. A imagem preenche, assim, a lacuna introduzida pela falta de relações fisiológicas suficientes com o meio que é acarretada pela prematuridade, e passa a mediar as relações do homem com o mundo: "O estágio do espelho constitui, justamente, um dos modos dessa relação" (Lacan, 1949/1966, p. 120). É referenciado nas deficiências causadas pela neotenia e pela fetalização que Lacan sublinha a discordância entre a imagem especular visualmente harmônica e a experiência subjetiva da criança, que é conformada pelas sensações de despedaçamento e falta de coordenação.

O estádio do espelho é um drama cujo impulso interno precipita-se da insuficiência para a antecipação - e que fabrica para o sujeito, apanhado no engodo da identificação espacial, as fantasias que se sucedem desde uma imagem despedaçada do corpo até uma forma de sua totalidade que chamaremos de ortopédica-e para a armadura enfim assumida de uma identidade alienante, que marcará com sua estrutura rígida todo seu desenvolvimento mental (Lacan, 1949/1966, p. 100).

De acordo com Jorge e Ferreira (2005, p. 39), "este texto adquire uma significação cada vez maior à medida que o ensino de Lacan avança”. Enquanto em 1938 o estádio do espelho era abordado no contexto estrito fornecido pelo complexo de intrusão, no texto de 1949 ele adquire um status independente, inclusive tornando-se "até mesmo o foco principal da teoria do imaginário” (Sales, 2005, p. 114). Por conseguinte, enquanto no texto sobre os complexos familiares o estágio do espelho era analisado a partir da presença do personagem do irmão como rival, este último passa, em 1949, "a ser substituído pela forma mais geral da presença do outro" (Sales, 2005, p. 114). Ademais, desde A agressividade em psicanálise (Lacan, 1948/1966), tem início na obra lacaniana, ainda que sutilmente, um movimento em direção à adoção de um ponto de vista estrutural, que culmina no texto de 1949:

Que ainda não fez nascer a ênfase no registro do simbólico e que é aplicado ao quadro da teoria do imaginário em seu momento mais característico; ou seja, é quando a reflexão sobre a imago ganha 
seus mais longos e ricos desdobramentos que seus impasses começam a se fazer sentir, dando lugar à necessidade de se lançar mão de uma outra dimensão de análise (Sales, 2005, p. 116).

Embora não o mencione explicitamente nem no artigo de 1938, nem no de 1949, Lacan, na elaboração do estádio do espelho, parte dos estudos de Wallon, principalmente aqueles publicados em As origens do caráter na criança (Wallon, 1934/1971) e no artigo Como se desenvolve na criança a noção de corpo próprio (Wallon, 1931/1963) e se apoia fortemente em suas teses. Levando isso em conta, é preciso abordar mais diretamente os conceitos de prematuração e de fase especular na psicologia de Wallon para melhor situar e avaliar o impacto de suas contribuições para as formulações lacanianas.

\section{Imagem especular $\mathbf{e}$ prematuração em Wallon}

Numa descrição detalhada do comportamento da criança, Wallon (1934/1971) apresenta como o bebê, entre os seis e os dezoito meses de idade, passa por diversas fases de desenvolvimento, até que seja capaz, num dado momento, de reconhecer sua imagem no espelho. Ele assinala que a criança, nessa fase, devido à sua condição de prematuração biológica, é absolutamente dependente do outro. Ao abordar o estado de imperícia em que se encontra o bebê humano nesse momento, Wallon observa que, no começo de seu desenvolvimento, o lactente não é ainda capaz de manter relações ativas com o ambiente físico. Antes dos quatro meses de idade, não pode ainda existir aquilo que Wallon chama de "espaço próximo" (aquele que pode ser ativamente visto pela própria criança) e nem o domínio dos movimentos que lhe permitiriam a estabilidade do tronco e a modificação da direção e da posição desses movimentos: "A delimitação do próprio corpo ainda é vaga e imprecisa, necessitando de uma maior exploração para poder primeiro reconhecer e individualizar as partes e posteriormente integrá-las em uma unidade" (Bastos, 2014, p. 37). Com isso, Wallon (1931/1963) busca evidenciar a insuficiência motora da criança pequena.

Nesse contexto, Wallon (1934/1971) aborda também o papel das emoções em manifestar o ciclo de atividade e de novas adaptações, para o que contribui a sensibilidade nascente que provém da atividade postural e de sua plasticidade essencial. Ele considera que a diferenciação entre o si mesmo e o outro ocorra progressivamente, sendo que tal diferenciação é mínima na criança pequena e se apaga ainda mais nos momentos de maior intensidade emocional: "A criança que caiu só chora sua dor ou seu medo ao saber estar sendo ouvida; mas, se escuta sozinha essas manifestações, as lágrimas logo cessam" (Wallon, 1934/1971, pp. 90-91). Isso se dá porque a emoção tem um grande poder de contágio sobre o outro, provocando reações semelhantes ou recíprocas e dificultando a indiferença frente a suas manifestações.

Nessa direção, Wallon (1934/1971) argumenta que existe uma dissociação entre os distintos domínios funcionais: o domínio interoceptivo seria o da sensibilidade visceral; já o proprioceptivo corresponderia às sensações relacionadas ao equilíbrio, às atitudes e aos movimentos, enquanto o domínio exteroceptivo (ou da sensibilidade) estaria voltado para as excitações de origem externa. As funções interoceptivas seriam as mais precoces, enquanto as exteroceptivas seriam as mais tardias. De acordo com Wallon, rapidamente os órgãos interoceptivos passam a servir como exteroceptivos, com o mundo externo assumindo uma relevância progressivamente maior para a criança na medida em que ligações sejam estabelecidas entre esses dois domínios de sua atividade.

Sobre a sensibilidade proprioceptiva, Wallon afirma que ela contribui significativamente para a elaboração da noção de corpo próprio, com suas primeiras manifestações surgindo já quando do nascimento. Ela se encontraria relacionada a um conjunto de funções que acompanha a evolução da atividade motora da criança desde os primórdios até as suas capacidades atuais: "correspondem, também, à solidariedade intersegmental do organismo no movimento e na estação de pé, à sua unidade, dinâmica na ação e estática em face das forças exteriores" (Wallon, 1934/1971, p. 164). Assim, os mecanismos superpõem-se progressivamente na execução dos movimentos, desde os mais rígidos até os mais flexíveis, sendo que estes últimos têm a capacidade de interromper a ação dos anteriores. Para Oliveira (2017), Wallon indica que, para a organização da consciência corporal, é necessário "que ocorra o desenvolvimento de um sistema coeso e sinérgico entre as sensibilidades interoceptivas, proprioceptivas e exteroceptivas" (p. 45).

Wallon (1934/1971) observa que, ao longo das primeiras semanas de vida, a criança não consegue executar com a cabeça os movimentos de esquiva. 
Ela começa a erguer a cabeça para o seio da nutriz apenas entre o primeiro e o segundo mês de vida. Os esforços para sentar-se ou para modificar uma posição incômoda são produzidos com êxito gradual apenas entre os quatro e os dez meses. Nesse intervalo relativamente grande de seis meses, as funções de equilíbrio são aquelas cujo desenvolvimento apresenta a rapidez de aquisição mais variável de uma pessoa para a outra. As primeiras tentativas de locomoção prenunciadas entre os oito e os nove meses têm como componentes iniciais os movimentos de virar-se, sentar-se e erguer-se nos pés, mas agarrando-se com as mãos. Como componentes subsequentes, aparecem as tentativas de deslizar para trás, de andar de rastos e, finalmente, de andar de quatro. A marcha de pé apenas será possível entre dez e dezoito meses. A partir dessas observações, o autor nota que a rapidez e o ritmo dessa evolução dos processos de equilíbrio compreendem diferenças individuais e que essa diversidade se encontra em todos os domínios nos quais a intervenção das funções de sinergia postural e motora ocorre. Enquanto a criança não domina seu equilíbrio, persiste a impotência motora.

Desde os primeiros momentos, as reações às impressões proprioceptivas se manifestam. Com cerca de cinco meses, há uma grande exaltação motora com relação a tudo que pode se apresentar como um sucesso, tal como quando a criança consegue, pela primeira vez, seguir com os olhos um objeto que se desloca. Com sete meses, sua agitação deixa de ser difusa, e as diferentes partes corporais não mais intervêm aleatoriamente ou por mera impulsividade motora. Com isso, os exercícios da criança bifurcam-se, com uns se voltando para o reconhecimento do próprio corpo e outros para os resultados externos de sua atividade.

As reações da criança em face de seu próprio corpo, de acordo com Wallon (1934/1971), apresentam, no plano sensório-motor, fases sucessivas, coincidentes com as de seu desenvolvimento exteroceptivo. Numa primeira etapa, dos três aos seis meses, a entrada como que aleatória dos membros em seu campo perceptivo parece surpreender a criança, provocando um esforço evidente de reconhecimento e de discriminação. Nesse ponto, Wallon faz referência à psicologia do desenvolvimento de Paul Guillaume (1926/1968), observando que, desde o final da $12^{\text {a }}$ semana de vida, a criança acompanha com o olhar o deslocamento das mãos. Já o interesse pelos movimentos dos pés e dos artelhos apenas ocorreria ao longo da $19^{a}$ semana. Ele observa que essa defasagem funcional possui um equivalente anatômico, a saber, a existência de uma diferença de aproximadamente três semanas entre os momentos em que as fibras nervosas correspondentes às mãos e aos pés se mielinizam: "Por conseguinte, relaciona-se, indiscutivelmente, a um atraso de maturação funcional essa diferença de vinte e seis dias entre as metades direita e esquerda do sistema nervoso" (Wallon, 1934/1971, p. 180). Por volta da $17^{\mathrm{a}}$ semana, a mão se torna uma parte do corpo privilegiada no desdobramento que se opera entre a criança e o objeto.

No entanto, para Wallon (1931/1963), apesar dos progressos, a criança ainda não possui nesse momento uma intuição primitiva e indispensável de seu corpo como um todo e em todos os seus aspectos. Por exemplo, a criança é incapaz, nessa fase, de prever o surgimento e os deslocamentos dos membros no campo visual. Além disso, as associações entre as distintas impressões correspondentes a essa intuição se formam somente de maneira muito parcial. Nesse período, o trabalho de integração entre as impressões provenientes da percepção externa e da sensibilidade proprioceptiva é tanto intenso quanto localizado, devido ao renitente estado de assinergia que ainda obstaculiza a integração imediata, num só e mesmo equilíbrio, de todas as atitudes e partes do corpo. Mas os membros que se apresentam em seu campo exteroceptivo não mais aparecem como um objeto qualquer e indiferente.

De acordo com Wallon (1934/1971), a fase seguinte do desenvolvimento se estende dos seis aos doze meses ou mais. Diante do mundo externo, a criança começa a reconhecer melhor a realidade, esperando dela determinados efeitos e dando início a sua atividade instrumental. Com relação a seu corpo, ela se envolve numa atividade de certo modo complementar, que tem como resultado a individualização e o predomínio da sensibilidade de relação sobre a sensibilidade orgânica e subjetiva: a criança adquire interesse em explorar seu corpo, em colocá-lo, de modo repetido e diverso, em contato consigo mesma, terminando por fazê-lo produzir, por meio de ações deliberadas, impressões igualmente antecipadas. Assim, as reações primitivas difusas vão se extinguindo, juntamente com as manifestações de surpresa. Referenciado no trabalho de Guillaume (1926/1968), Wallon identifica a ação de segurar os pés com as mãos, de manusear os artelhos, levando-os à 
boca, a partir do $6^{\circ}$ mês. É ao longo de sua atividade lúdica que a criança experimenta a diferença entre a superfície sensível oferecida a sua atividade pelas várias partes do corpo e pelos objetos externos.

Wallon (1934/1971) prossegue observando que outra fase, parcialmente sobreposta à anterior, evidencia como, a princípio, a criança identifica melhor os órgãos de outra pessoa do que os seus. Além disso, quando finalmente torna-se capaz de representar seus órgãos, trata-os, de início, como coisas estranhas e, a seguir, como uma espécie de personalidades anexas, como que numa forma ingênua de animismo. Com isso, a criança começa a descobrir as semelhanças entre os movimentos próprios e os alheios, como, por exemplo, quando, em torno de 55 semanas, estende as mãos para sua face e dirige o olhar para suas próprias mãos após observar com muita atenção alguém comendo, seguindo com os olhos todos os seus movimentos, mas continua segurando as mãos dos pais para movimentar suas articulações. Ou então:

Ainda com 1 ano e 3 meses, morde um dedo e solta um grito de surpresa. Aos 19 meses, ao lhe dizerem "Dá o sapato", ela apanha o sapato que perdera e o entrega. Diz-se, então: “Dá o pé”, e ela agarra o pezinho com as mãos e tenta estendê-lo. Aí temos, sem dúvida, um caso de perseverança, favorecido pela fórmula idêntica das duas ordens dadas consecutivamente. Contudo, a insistência com que a criança pretende destacar o pé do corpo indica, realmente, uma falta de coesão entre as impressões que deste possui e o sentimento de sua própria atividade (Wallon, 1931/1963, pp. 139-140).

De acordo com Bastos (2014), esse exemplo permite perceber que ainda não existe na criança dessa fase a possibilidade de representação do corpo como uma só unidade, pois ela ainda não possui a aptidão simbólica, que é a condição imprescindível da capacidade de representação corporal. As partes do corpo da criança são gradualmente reconhecidas e individualizadas, mas não estão integradas desde o início na sua individualidade física. Por isso, a criança em torno de um ano e onze meses ainda tem a ilusão de independência e autonomia de seus próprios órgãos vitais: "Assim, o animismo da criança pode levá-la a dar tratamento igual a seu próprio corpo e aos objetos exteriores" (Wallon, 1934/1971, p. 187).
É nesse ponto que Wallon passa, então, a descrever o comportamento da criança quando vê sua imagem refletida no espelho. Ele observa que seu modo de reagir a essa imagem constitui a contraprova que evidencia os níveis evolutivos que se intercalam até seu acesso à intuição corporal integral e de todos os elementos corporais relacionados com sua personalidade física: "Trata-se de saber como a criança se torna capacitada a reconhecer como seu o aspecto exteroceptivo, traduzido pelo espelho da maneira mais completa e evidente" (Wallon, 1934/1971, p. 188). Esse desenvolvimento inclui, em princípio, dois tempos muito simples: a percepção da imagem e a capacidade de relacioná-la a si própria.

Com o objetivo de remontar aos primórdios desta evolução, o autor recorre a exemplos tomados do comportamento animal. Ele observa que a reação de um macaco diante de um espelho é imediatamente correr e mostrar raiva por não encontrar absolutamente nada para segurar, recusando-se, a partir daí, a olhar para a superfície polida. Esse contexto pareceria, inicialmente, um verdadeiro ato de conhecimento, e não um experimento frustrado: "Haveria, então, um desdobramento, embora fugaz, entre a percepção e a adesão, isto é, o nascimento da representação em face do real" (Wallon, 1934/1971, p. 191). Respaldando-se em Köhler, ele afirma que os chimpanzés já seriam, assim, capazes de se reconhecer num retrato, o que configura um estágio a que a criança não acede imediatamente. Apenas mais tarde superará o chimpanzé, quando conseguir reconhecer o real na imagem, mas sabendo dissociar as coisas da sua representação de forma definitiva.

Wallon (1931/1963) passa, a seguir, a se concentrar na evolução do comportamento evolutivo da criança diante da imagem especular, observando que, até o final do $3^{\circ}$ mês de vida, ela permanece insensível às imagens formadas no espelho. A reação a essas imagens são impossíveis numa idade em que, justamente, as sinergias dos órgãos sensoriais ainda não estão bem reguladas e coordenadas, evidenciando um equilíbrio muito precário, a ponto de embaralharem as percepções da criança diante de qualquer posição, sentada ou em pé, que apresente alguma dificuldade, mesmo que pequena: "Desse modo, a criança não é sensível à sua imagem nos primeiros dias após o nascimento. É necessária certa maturação dos órgãos para coordenar sinergeticamente seu equilíbrio (função postural)" (Oliveira, 2017, p. 52). 
Wallon nota que é apenas ao longo do quarto mês que a criança se sente provocada pela imagem refletida no espelho, a ponto de nela fixar seu olhar, mas sem manifestar, inicialmente, nenhum interesse pela fisionomia. Já na $17^{\text {a }}$ semana a criança encara sua imagem especular como encararia um estranho visto pela primeira vez, sorrindo após cerca de três dias. Após quinze dias, passa a ocorrer manifestação de interesses, o que já revela uma criança sensível à representação da fisionomia humana. Mas é necessário aguardar o sexto mês de vida para que a criança consiga associar sua imagem refletida no espelho a outras reações além das manifestações estritamente mímicas e afetivas. Wallon observa que, inicialmente, essa passagem só ocorre sob o impacto de uma circunstância externa. Ele comenta sobre a observação do filho de Darwin, que sorri em face de sua imagem e da imagem de seu pai, que ele vê no espelho: "Sem embargo, ao ouvi-lo falar, às suas costas, vira-se, surpreendido. Portanto, ainda não sabia fazer coincidir, no tempo e no espaço, o aspecto da presença real do pai e o reflexo do mesmo no espelho" (Wallon, 1934/1971, p. 192). Foi precisamente o movimento provocado por uma excitação auditiva acrescida à situação, por acaso, que impactou a primeira confrontação evidenciada pelo exemplo dado. Nesse ponto, ele destaca algo que já fora observado por diferentes pesquisadores: o comportamento de se voltar para a pessoa vista pela criança no espelho. Nesse movimento, o que está em jogo é a verificação de uma relação: trata-se de um ato de conhecimento. Junto com a expressão de surpresa, é possível observar uma fisionomia muito atenta, evidenciando a realização de algo novo, que resolve uma dificuldade ao integrar, num plano superior da atividade mental, o que até então estava descoordenado.

No entanto, mesmo com esse progresso, não há ainda uma completa transposição da justaposição, e a criança continua a atribuir ao objeto e à imagem uma realidade independente, o que se manifesta na ilusão de poder agarrar a própria imagem e na demonstração de surpresa por esta parecer superpor-se ao objeto. De acordo com Wallon, é possível ver nesse comportamento uma insuficiência na percepção: tratar-se-ia de "uma insuficiente discriminação entre o que é volume no espaço e a imagem surgida na superfície brilhante do espelho. Todavia, a insuficiência não é de ordem sensorial, pois à criança jamais acontece tomar a imagem pela pessoa" (Wallon, 1934/1971, p. 194).
Dessa forma, para ele, "relacionar por um gesto de atribuição a imagem do espelho à pessoa ainda não significa fundi-la na existência dessa pessoa, a ponto de ver nisso uma simples aparência" (Wallon, 1934/1971, p. 194). Essa insuficiência resultaria na incapacidade da criança em ver sua própria imagem como mera aparência, assim como para conceber a coincidência súbita da imagem no vidro e da imagem no espaço. A realidade atribuída à imagem refletida no espelho é completa, tanto que na $35^{\text {a }}$ semana a criança olha para a imagem sempre que a chamam pelo nome. Ademais, entre a $41^{\text {a }}$ e $44^{\text {a }}$ semanas, a criança ri e estende os braços para a imagem especular sempre que a vê. Indubitavelmente, é capaz de ter uma visão direta de seu corpo, mas somente de alguns fragmentos, jamais unificados, evidenciando uma visão parcelada, em vez de uma imagem homogênea e coerente dos órgãos em conjunto e, por conseguinte, do corpo total. O autor nota, pois, que a representação corporal só pode se formar ao se exteriorizar. É por meio de pontos de referência, "utilizando analogias e assimilação com o que já sabe perceber e representar distintamente, que a criança chega a individualizar e a discernir os diferentes aspectos sob os quais lhe é permitido adquirir uma representação de si mesma" (Wallon, 1934/197, pp. 196-197). E continua:

Para que consiga de maneira satisfatória unir seu próprio eu no espaço, será preciso situar o eu exteroceptivo de modo a tornar a percepção essencialmente irrealizável. Pois tão logo a veja, sua imagem deixa de coincidir no espaço com seu próprio corpo e deve considerá-la sem realidade; e logo que supõe a realidade de seu aspecto exteroceptivo, ela o deve encarar como inacessível a seus próprios sentidos. Necessidade dupla: admissão de imagens com aparência de realidade; afirmação de imagens que se furtam à percepção. . . . É o prelúdio da atividade simbólica, segundo a qual o espírito consegue transmutar os dados da sensibilidade em universo (Wallon, 1934/197, p. 199).

Wallon observa ainda que a imagem refletida no espelho só se torna estritamente simbólica ao se esvaziar de existência: "Isso implica que, gradualmente, a noção do corpo próprio adquira uma dimensão espacial-objetiva" (Oliveira, 2017, p. 53). Apoiando-se, 
mais uma vez, em Guillaume, Wallon prossegue, observando que, entre os doze e os quinze meses, a criança se põe a executar diante do espelho gestos que já fazem parte de seu repertório, mas os executa com muito mais incorreção e dificuldade, evidenciando semelhança no movimento, mas diferença no ato. Isso ocorre porque sua regulagem é alterada, no que, diferentemente do automatismo anterior, trata-se agora de ações bem mais mediatas, que devem se submeter às orientações bem mais abstratas das representações e dos símbolos: "A criança parece prosseguir em todos os domínios o inventário das alterações impostas a sua atividade ou aos seus conhecimentos pela nova aptidão" (Wallon, 1934/1971, p. 200).

Ao longo da $60^{\mathrm{a}}$ semana, quando a criança é convidada a apontar para a mãe, começa por identificá-la no espelho para, em seguida, entre risos, voltar-se para ela, num comportamento totalmente distinto daquele apresentado no sexto mês de vida. Esse gesto se revela diferente daquele do sexto mês, porque agora, ao buscar primeiramente a presença da mãe no espelho, a criança joga com a dualidade entre a pessoa e a imagem, que já é capaz de reconhecer, mesmo que maliciosamente finja conceder precedência à imagem. Em outras palavras, nesse novo momento, ao contrário do que acontece antes, a criança passa a reconhecer nitidamente a irrealidade e o caráter estritamente simbólico da imagem especular.

Wallon observa um comportamento típico da $57^{\text {a }}$ semana de vida que é digno de nota, por se assemelhar àqueles apresentados pelo chimpanzé em circunstâncias idênticas: uma criança se observa com um espelho diante do rosto e, a seguir, passa a mão por trás, com o objetivo de tocar a suposta pessoa cuja imagem está olhando. Ou, quando com o espelho entre as mãos, vira-o e o contempla pelos dois lados. Depois de alguns minutos, novamente diante do espelho, repete o comportamento descrito, mas, no dia seguinte, se desvia reiteradamente dele. Seguindo as ideias de Bühler (1927, 1928), Wallon observa que esse comportamento ocorre na assim chamada “idade do chimpanzé" (Wallon, 1931/ 1963, p. 148), em que se verifica uma semelhança entre as soluções instrumentais do chimpanzé e as da criança ao buscarem vencer os obstáculos que se opõem à realização de seus desejos.

Pode-se constatar, assim, como Wallon descreveu detalhadamente o drama da prematuração presente no cerne das reações à imagem do corpo próprio.
Como se comentou acima, essas contribuições não foram explicitamente mencionadas nos escritos lacanianos entre 1936 a 1949. No entanto, é possível identificar o impacto dessas contribuições nesses trabalhos. Cabe avaliar, então, a título de conclusão, a função dessas referências e o estilo geral da recepção das ideias de Wallon por Lacan.

\section{Discussão}

Wallon é considerado um dos principais nomes da psicologia infantil na França, tendo, entre outras coisas, contribuído com testes inovadores, a partir dos quais procurou identificar as questões centrais que atuam no desenvolvimento inicial da vida psíquica (Gratiot-Alfandéry, 2010), inclusive com implicações para o campo da educação (Galvão, 1998). No contexto da investigação da função e implicações da descoberta da imagem especular na criança, não apenas ele, mas a psicologia do desenvolvimento da época em geral, passa a estudar o comportamento infantil na sua relação com a imagem corporal, com o objetivo também de evidenciar as diferenças entre a inteligência dos seres humanos e a dos outros primatas (Bühler, 1927, 1934; Guillaume, 1926/1968). No que se refere às contribuições de Wallon para as formulações lacanianas sobre esse tema, destaca-se o artigo "Comment se développe chez l'enfant la notion du corps propre” (Wallon, 1931/1963) e o livro As origens do caráter na criança, que traz este artigo como uma das suas três partes - aquela intitulada "Consciência e individualização do corpo próprio”.

Como se viu, o artigo de Lacan de 1938 sobre os complexos familiares, que retoma as ideias do trabalho apresentado em 1936, não faz qualquer menção a Wallon. Além disso, nos outros artigos que desenvolvem a temática do estágio do espelho, Wallon tampouco aparece como referência. Apesar disso, Wallon dedicou-se ao tema antes de Lacan, abordando diversos elementos que podem ser identificados na abordagem lacaniana. O fato de esses trabalhos serem bem conhecidos na época nos mesmos círculos frequentados por Lacan sugere fortemente a hipótese da influência de Wallon sobre as ideias de Lacan no período, além de haver indícios de uma comunicação direta entre os dois, como quando Wallon convida Lacan para escrever o verbete sobre a família em 1938. É essa presença de Wallon nas elaborações lacanianas que se trata de examinar em maior detalhe. 
A respeito da hipótese da influência walloniana sobre Lacan, Roudinesco (1994) afirma que ela não se dá apenas por meio do livro As origens do caráter na criança (Wallon, 1934/1971), mas também de sua tese de doutorado, A criança turbulenta (Wallon, 1925/2007). Borch-Jacobsen (1991) argumenta que a descrição lacaniana do estágio do espelho está distante de ser realmente original e que a verdadeira origem dessa temática deve ser atribuída a Wallon, dado que este, em 1931, já havia discutido o tema e alcançado conclusões bem parecidas. Barzilai (2004) afirma que o interesse de Lacan por Wallon se manifesta já por volta de 1930, época em que Lacan teria lido sua monografia sobre Bühler, Darwin, Guillaume, Köhler e Preyer. Ogilvie (1991) argumenta que a primeira abordagem lacaniana do estágio do espelho deve ser inserida numa tradição que começa com Wallon em 1931 e que Lacan não pode ignorar, uma vez que o artigo referido é um dos primeiros estudos sistemáticos a abordar o comportamento da criança diante da imagem especular. De fato, "as observações detalhadas de Wallon estabeleceram claramente um paradigma conceitual para a compreensão de Lacan do estágio do espelho" (Oliveira, 2017, p. 55).

Inegavelmente, as descrições sobre a conquista de uma imagem unificada do corpo por parte da criança são algumas das concepções wallonianas mais influentes em Lacan: "Ambos afirmam que a forma corporal, a unidade da imagem especular ou a gestalt são indispensáveis ao processo de maturação" (Oliveira, 2017, p. 55), sendo que o espelho aparece em ambos como o "elemento mediador, fazendo a intercessão entre a imagem corporal parcial e fragmentada do início da vida da criança" (Wallon, 1934/1971, p. 230) e aquela unificada. Oliveira aponta também o comportamento da criança diante do espelho como uma das concepções que reverberam entre os dois autores, enfatizando as diferenças nas capacidades mentais entre as diversas espécies, assim como entre as crianças em diferentes fases de seu desenvolvimento. De maneira semelhante a Wallon, Lacan contrasta o comportamento da criança com o do chimpanzé em seu trabalho de 1949. Por último, para a autora, assim como Wallon, Lacan também menciona os experimentos de outros psicólogos que publicaram suas observações na década de 1930, tais como Charlotte Bühler.

No entanto, é possível explorar um pouco mais a função da mediação do espelho, conferindo mais visibilidade à condição de prematuridade do sujeito humano no cerne da temática da assunção da imagem corporal. Lacan, ao elaborar sua teoria do estágio do espelho, ressalta que o júbilo da criança diante da percepção da imagem própria contrasta com a experiência subjetiva do corpo sentido como despedaçado, que se deve justamente a sua prematuridade. A imagem, assim, faria o bebê se sentir como uma totalidade. Os comportamentos que evidenciam essa prematuridade são aqueles observáveis na criança durante a fase do espelho e que acompanham, de algum modo, a reação especular.

Esses comportamentos foram evocados minuciosamente por Wallon em 1931 e, mais extensamente, em 1934. Neste último trabalho, na parte intitulada "Consciência e individualização do corpo próprio”, é possível identificar o tema da insuficiência motora da criança pequena como pano de fundo para o desenvolvimento da noção de corpo próprio e da imagem especular. Mas, considerando essa obra como um todo, é também possível identificar que o tema da insuficiência motora a permeia do início ao fim. Pode-se concluir, assim, que o tema do desenvolvimento da imagem especular é um tópico desenvolvido por Wallon no âmbito da temática mais ampla da insuficiência motora da criança. Embora ele não explicite o termo "prematuração", a questão da prematuridade do sujeito humano sugerida pela exploração da insuficiência motora se encontra no cerne do livro de 1934. A fase especular é descrita por ele como relacionada à prematuração. Quanto a isso, cabe observar que o livro A criança turbulenta (Wallon, 1925/2007) também aborda o tema da insuficiência motora.

A criança turbulenta foi o trabalho inicial do autor no campo da psicologia infantil. Wallon observa e analisa detalhadamente 214 crianças atendidas em um posto psiquiátrico nos subúrbios de Paris, na faixa etária entre 2 e 3 anos e com graves distúrbios psicológicos, tais como delinquência, perversidade e instabilidade. Na primeira parte da obra, ele descreve os estágios de desenvolvimento psicomotor: emotivo, sensitivo-motor e projetivo. Já na segunda parte, são descritas as síndromes psicomotoras: debilidade motora, assinergia motora e mental, hipertonia, automatismo emotivo-motor e insuficiência frontal. Wallon evidencia que, para o conhecimento da natureza das funções e suas relações, uma análise neurológica não seria suficiente, sendo preciso considerar também a influência do meio. 
Por isso, as insuficiências psicomotoras deveriam ser compreendidas no contexto de um aparato biológico em estruturação contínua e em constante integração com o meio, numa concepção psicobiológica do desenvolvimento. Cabe notar que o sujeito walloniano é um sujeito social, estando a mediação social na base de seu desenvolvimento (Dantas, 1992).

Retomando a análise walloniana do desenvolvimento da noção de corpo próprio, fica evidente quanto Wallon aborda esse desenvolvimento na criança sobre o pano de fundo fornecido pelo tema da prematuração. Pode-se afirmar, então, que o autor considera a noção de corpo próprio indispensável para os progressos posteriores da consciência, indicando que o sujeito humano nasce numa condição de imperícia. Essa condição de ausência de recursos para a sobrevivência torna necessário um adulto cuidador para a satisfação das necessidades vitais básicas. Inicialmente, linguagem é um simples "grito", que possui um valor expressivo, mas não um conteúdo representativo. Trata-se de uma primeira forma de linguagem essencialmente emocional e imperativa, no que, devido a sua condição de imperícia, o bebê depende da intervenção dos outros para satisfazer suas necessidades mais prementes $\mathrm{e}$ busca a realização imediata de seus desejos. A descarga emocional manifestada por choros, gritos e gestos involuntários é a via encontrada pelo bebê para expressar sua necessidade de alimento, sono etc. - enfim, seu estado de desconforto. Assim, para Wallon (1941/1955), a emoção está na base estrutural da consciência, embora venha se diferenciar dela cada vez mais ao longo do desenvolvimento. Bastos (2003) argumenta que as emoções seriam, num primeiro momento, puramente fisiológicas. Mas essas manifestações vão sendo nomeadas e interpretadas pelo adulto cuidador, que já percebe, nelas, um apelo do bebê. Aos poucos, tem lugar o compartilhamento dos significados atribuídos às manifestações emocionais do bebê, viabilizando o estabelecimento de uma comunicação mais clara entre eles.

Assim sendo, Wallon (1934/1971) observa que o bebê permanece incapaz de manter uma atividade de relação com o meio físico durante meses, na medida em que lhe faltam, além da percepção e da discriminação do mundo externo, os movimentos coordenados e adequados a sua finalidade. Nessa fase, a delimitação do próprio corpo ainda é vaga e imprecisa. Ao final de seu primeiro ano de vida, o bebê humano já esboça um primeiro recorte corporal, adquirindo uma consciência relativa das partes de seu corpo, ainda que não consiga integrá-las numa representação corporal unificada. A representação corporal somente se constrói por meio de etapas graduais. Por meio das atividades motoras, a criança consegue aceder ao reconhecimento progressivo das formas corporais.

Sobre o tema da prematuração presente no cerne da abordagem walloniana do desenvolvimento da noção de corpo próprio na criança, Bastos (2014) argumenta que o trabalho de Wallon evidencia que a possibilidade de representação do corpo suscita um júbilo na criança, que ainda é fisiologicamente imatura, mas demonstra uma aptidão psicológica complexa nessa conquista. Esse júbilo é intenso e resulta do reconhecimento da própria imagem pela criança, efeito de um processo de identificação. Nessa direção, Wallon indicaria haver nesse ponto uma antecipação psicológica sobre a fisiologia. Essa conquista é vital para o desenvolvimento da consciência e da identidade (Wallon, 1934/1971). A constituição do eu é uma conquista gradual a partir de um processo de diferenciação, oposição e complementaridade: o eu e o outro são entendidos como um par antagônico e dialético, que se complementa pela oposição e possui a mesma filiação (Wallon, 1975). A imagem corporal unificada produz, pois, a ilusão de um domínio que, embora fictício, deixa a criança radiante.

\section{Conclusão}

É possível, assim, identificar elaborações wallonianas sobre o tema da prematuração no cerne da teoria lacaniana do estágio do espelho. Inegavelmente, Lacan evoluiu muito ao longo da sua trajetória. Para Julien (1993), o estágio do espelho está inscrito numa longa série de desenvolvimentos. Esse percurso não é uniforme; mas é possível esboçar uma periodização:

De 1938 a 1952, em cada artigo publicado, Lacan expõe a especificidade do modo imaginário. Não é o ilusório, mas um objeto psíquico, com sua própria causalidade, não redutível ao orgânico. 2) De 1953 a 1960, Lacan, ao descrever o efeito do simbólico sobre o imaginário, modifica a apresentação do estágio do espelho em seus artigos e seminários, para relativizá-lo enquanto submetido à ordem simbólica. Ele a formaliza com a escrita do esquema óptico. 3). Porém, de 1961 a 1980, ele dá ao estágio outra escrita, 
a topológica, com o olhar como objeto a, em lugar do Outro (Julien, 1993, p. 26).

Levando em conta essa evolução, uma análise crítica pertinente da contribuição de Wallon nos passos iniciais de Lacan - a saber, a investigação do tema do narcisismo que culmina com sua primeira teoria do imaginário - não pode ser feita baseada no último
Lacan. Tratou-se aqui apenas de identificar as implicações das conexões teóricas entre a teoria do imaginário desenvolvida por Lacan em sua obra inicial e a psicologia do desenvolvimento de Wallon e de evidenciar a relevância dessas contribuições nesse momento específico da construção do corpus lacaniano - uma relevância que não parecia ter sido ainda suficientemente contemplada pela literatura da área.

\section{Referências}

Barzilai, S. (2004). Lacan and the matter of origins. Stanford: Stanford University Press.

Bastos, A. B. B. I. (2003). A construção da pessoa em Wallon e a constituição do sujeito em Lacan. Petrópolis, RJ: Vozes, 2003.

Bastos, A. B. B. I. (2014). Wallon e Vygotsky: Psicologia e educação. São Paulo, SP: Edições Loyola.

Bühler, K. (1927). Die geistige Entwicklung des kindes. Jena: G. Fischer.

Bühler, K. (1928). Abriss der geistigen Entwicklung des kindes. Leipzig: Quelle \& Meyer.

Bühler, C. (1934). El desarrollo psicológico del niño. Buenos Aires: Losada. (Trabalho original publicado em 1927)

Dantas, H. (1992). A afetividade e a construção do sujeito na psicogenética de Wallon. In H. Dantas, Y. La Taille, \& M. Kohl, Piaget, Vygotsky e Wallon: teorias psicogenéticas em discussão (pp. 85-98). São Paulo, SP: Summus.

Galvão, I. (1998). Henri Wallon: uma concepção dialética do desenvolvimento infantil. Rio de Janeiro, RJ: Vozes.

Gratiot-Alfandéry, H. (2010). Henri Wallon. Recife, PE: Massangana.

Guillaume, P. (1968). L'imitation chez l'enfant. Paris: PUF. (Trabalho original publicado em 1926)

Jalley, É. (2011). Freud, Wallon, Lacan: A criança no espelho. Rio de Janeiro, RJ: Cia de Freud.

Jorge, M. A. C., \& Ferreira, N. P. (2005). Lacan: o grande freudiano. Rio de Janeiro, RJ: Zahar.

Julien, P. (1993). O retorno a Freud de Jacques Lacan: aplicação ao espelho. Porto Alegre, RS: Artes Médicas Sul.

Lacan, J. (1966). Au-delà du “Principe de réalité”. In Écrits (pp. 73-92). Paris: Éditions du Seuil (Trabalho original publicado em 1936)

Lacan, J. (1966). L'agressivité em pschanalyse. In Écrits (pp. 101-124). Paris: Éditions du Seuil. (Trabalho original publicado em 1948)

Lacan, J. (1966). Le stade du miroir comme formateur de la fonction du Je. In Écrits (pp. 93-100). Paris: Éditions du Seuil. (Trabalho original publicado em 1949)

Lacan, J. (1966). Propos sur la causalité psychique. In Écrits (pp. 151-193). Paris: Éditions du Seuil. (Trabalho original publicado em 1950)

Lacan, J. (1985). Os complexos familiares. Rio de Janeiro, RJ: Zahar. (Trabalho original publicado em 1938)

Ogilvie, B. (1991). Lacan: a formação do conceito de sujeito. Rio de Janeiro, RJ: Zahar.

Oliveira, R. H. (2017). A gênese da teoria lacaniana do estágio do espelho: os materiais para construção (Dissertação de mestrado). Universidade Federal de Juiz de Fora, Juiz de Fora, MG.

Roudinesco, E. (1985). História da psicanálise na França: A batalha dos cem anos-1925-1985 Vo. 2). Rio de Janeiro, RJ: Zahar.

Roudinesco, E. (1994). Jacques Lacan: esboço de uma vida, história de um sistema de pensamento. São Paulo, SP: Companhia das Letras.

Sales, L. S. (2005). Posição do estágio do espelho na teoria lacaniana do imaginário. Revista do Departamento de Psicologia-UFF, 17(1), 113-127. 
Severino, A. (2007). Teoria e prática científica. In A. Severino, Metodologia do trabalho científico (pp. 99-126). São Paulo, SP: Cortez.

Simanke, R T. (2002). Metapsicologia lacaniana: Os anos de formação. Curitiba, PR: Discurso Editorial.

Verstegen, I. (2015). Lacan and gestalt theory, with some suggestions for cultural studies. Gestalt Theory, 37(3), 273-286.

Wallon, H. (1955). A evolução psicológica da criança. São Paulo, SP: Martins Fontes. (Trabalho original publicado em 1941)

Wallon, H. (1963). Comment se développe chez lénfant la notion du corps propre. Enfance, 16(1-2), 121-150. (Trabalho original publicado em 1931)

Wallon, H. (1971). As origens do caráter na criança. São Paulo, SP: Difusão Europeia do Livro. (Trabalho original publicado em 1934)

Wallon, H. (1975). Objetivos e métodos da psicologia. Lisboa: Editorial Estampa.

Wallon, H. (2007). A criança turbulenta. Rio de Janeiro, RJ:Vozes. (Trabalho original publicado em 1925)

\section{Crístia Gonçalves Lopes Corrêa}

Bolsista de Pós-Doutorado Júnior (PDJ) pelo CNPq no Programa de Pós-Graduação em Psicologia da Universidade Federal de Juiz de Fora. Doutorado e Mestrado em Educação pela Universidade Federal de Juiz de Fora. Mestre em Filosofia e Ética da Saúde Mental pela University of Warwick, Inglaterra. Graduação em Psicologia pelo Centro de Ensino Superior de Juiz de Fora. Membro da Associação Mundial de Psiquiatria, Juiz de Fora - MG. Brasil.

E-mail: crlopes2001@yahoo.com.br

(1) https://orcid.org/0000-0002-6303-510X

\section{Richard Theisen Simanke}

Professor titular do Departamento de Psicologia da Universidade Federal de Juiz de Fora e docente e orientador de mestrado e doutorado dos Programas de Pós-Graduação em Psicologia e Filosofia da mesma universidade. É bolsista de produtividade em pesquisa do CNPq e autor de diversos livros e artigos na área de história e epistemologia da psicologia e da psicanálise, Juiz de Fora - MG. Brasil.

E-mail: richardsimanke@uol.com.br

(1) https://orcid.org/0000-0002-6405-8776

Este artigo foi produto da Pesquisa financiada pelo CNPQ na modalidade de Pós-Doutorado Júnior no Programa de Pós- Graduação em Psicologia da Universidade Federal de Juiz de Fora (UFJT)

Endereço para envio de correspondência:

Departamento de Psicologia - Instituto de Ciências Humanas - Universidade Federal de Juiz de Fora,

Campus Universitário S/N, Martelos

CEP: 36036330. Juiz de Fora - MG. Brasil.

Recebido 26/05/2018

Aceito 01/06/2020

Received 26/05/2018

Approved 01/06/2020

Recibido 26/05/2018

Aceptado 01/06/2020 
Como citar: Corrêa, C. G. L., \& Simanke, R. T. (2020). O Legado Walloniano em Lacan: o Estágio do Espelho e a Prematuração. Psicologia: Ciência e Profissão, 40, 1-15. https://doi.org/10.1590/1982-3703003201009

How to cite: Corrêa, C. G. L., \& Simanke, R. T. (2020). The Wallonian Legacy in Lacan: the Mirror Stage and Prematurity. Psicologia: Ciência e Profissão, 40, 1-15. https://doi.org/10.1590/1982-3703003201009

Cómo citar: Corrêa, C. G. L., \& Simanke, R. T. (2020). El Legado Walloniano em Lacan: el Estádio del Espejo y la Prematuración. Psicologia: Ciência e Profissão, 40, 1-15. https://doi.org/10.1590/1982-3703003201009 